\section{ORIGINAL RESEARCH}

K. Aydin

S. Kircan

S. Sarwar

O. Okur

E. Balaban

\title{
Smaller Gray Matter Volumes in Frontal and Parietal Cortices of Solvent Abusers Correlate with Cognitive Deficits
}

\begin{abstract}
BACKGROUND AND PURPOSE: Abuse of toluene-containing organic solvents by inhalation is a prevalent practice among adolescents. Long-term abuse of toluene causes cognitive deficits. The mechanism of cognitive deficits induced by long-term toluene abuse has not yet been defined. In the current study, we assessed the effects of chronic toluene abuse on cortical gray matter volume and the association between cognitive impairment and cortical gray matter volume distribution in chronic toluene abusers.
\end{abstract}

MATERIALS AND METHODS: Fifteen toluene abusers and 20 healthy control subjects matched in sex, age, education level, and handedness were investigated by structural MR imaging. The cognitive states of the subjects were assessed by using the third edition of the Wechsler Intelligence Scale for Children (WISC-III). The voxel-based comparison and correlation analyses of MR images were performed by using SPM5 software.

RESULTS: The voxel-based morphometric analysis revealed that toluene abusers had significantly lower gray matter volumes in the bilateral frontotemporal and right parietal cortices. In addition, the lower gray matter volumes in the frontal and parietal regions correlated with the duration of toluene abuse. There was a positive correlation between the WISC performance scale scores and gray matter volumes in the frontal and parietal cortices of the abusers.

CoNcLusions: The results of the current study demonstrate that chronic toluene abusers have smaller gray matter volumes than nonabusers in various regions of the brain. Moreover, the cognitive deficits are associated with the lower gray matter volumes in the frontal and parietal cortices of chronic toluene abusers.

$\mathbf{T}$ he first reports of solvent abuse were published in the 1950s in the United States. ${ }^{1}$ Today, abuse of organic solvents has become an important health and social problem in the developed as well as the developing countries. ${ }^{2-4}$ Solvent abuse is particularly prevalent among adolescents. ${ }^{4,5}$ Schoolbased surveys conducted in the United States and Australia revealed the rates of experimental solvent use up to $26 \%$ during adolescence. ${ }^{2}$ The common methods of solvent abuse among adolescents are "sniffing" (direct inhalation of solvent from a container), "huffing" (inhalation of solvent by holding a soaked rag over the nose and mouth), and "bagging" (inhalation of solvent from a plastic bag). It is known that long-term solvent use has significant toxic effects on the human central nervous system. ${ }^{2,4,6-9}$ Despite its high prevalence and serious health and social consequences, today relatively little is known about the mechanism of solvent-induced central nervous system toxicity. ${ }^{2,4}$

Toluene, also known as methylbenzene, is a lipid-soluble aromatic hydrocarbon that is commonly used as a solvent in industry. It is also a common component of many household

\section{Received April 20, 2009; accepted after revision May 9.}

From the Departments of Neuroradiology (K.A.) and Radiology (S.S., E.B.), Istanbul Medical Faculty, Istanbul University, Istanbul, Turkey; Department of Psychiatry (S.K.), Bakirkoy State Hospital, Istanbul, Turkey; and Biomedical Engineering Institute (0.0.), Bogazici University, Istanbul, Turkey.

This work was supported by the Turkish Academy of Sciences (TUBA-GEBIP award fund). Please address correspondence to Kubilay Aydin, MD, Adnan saygun Caddesi, M. Salihrustu bey sokak, Ulus, konaklari, No:8/12, Ulus, Istanbul, Turkey; e-mail: dr.aydink@ superonline.com or aydink@istanbul.edu.tr

Indicates open access to non-subscribers at www.ajnr.org

DOI 10.3174/ajnr.A1728 products such as paint thinners, spray paints, ink, and glue. After inhalation, toluene is easily absorbed by the lungs. Because of its high lipid solubility, it readily diffuses and accumulates in tissues with a high lipid composition, such as the central nervous system. Toluene is thought to be the cause of central nervous system toxicity in solvent abusers. ${ }^{6,10}$ Several previous studies have shown that regular long-term abuse of toluene causes severe and irreversible cognitive impairment. ${ }^{4,11-13}$ Hormes et $\mathrm{al}^{7}$ reported that among chronic toluene abusers, the cognitive deficits are inattention, apathy, memory dysfunctions, and visuospatial impairment. Rosenberg et al $^{12}$ compared the cognitive abilities of chronic toluene abusers with those of alcohol abusers and cocaine users. They found significant deficits in working memory and executive function in the toluene abusers.

Nevertheless, the exact pathologic mechanism of cognitive impairments caused by chronic toluene exposure has not yet been defined. Because of prevalent comorbid drug use among solvent abusers, the findings reported in the limited numbers of autopsy cases are controversial and inconclusive. ${ }^{4,6,9} \mathrm{Sev}$ eral neuroimaging studies have been conducted to investigate the neurotoxic effects of toluene abuse. MR imaging studies reveal that chronic toluene abuse causes T2-weighted hyperintense white matter lesions starting in the periventricular region during the early years of abuse, and these lesions later spread to subcortical U fibers. ${ }^{2,4,12,14-18}$ Dilation of cortical sulci, thinning of the corpus callosum, and thalamic T2weighted hypointensity were the other MR imaging findings in chronic solvent abusers. ${ }^{14,19,20}$ The presence of white matter lesions on cranial MR imaging was significantly associated with the greater cognitive impairment among the chronic toluene abusers. ${ }^{12}$ Thus, the results of previous neuroimaging 
studies point to white matter as the target tissue for the development of cognitive impairment in chronic toluene abusers. Consistent with this hypothesis, Filley et $\mathrm{al}^{11}$ found a significant correlation between the severity of white matter changes on MR imaging and the severity of cognitive impairment. Furthermore, Aydin et $\mathrm{al}^{14}$ reported an association between the type of white matter lesions on MR imaging (restricted or diffuse) and both duration of toluene abuse and neurologic deficits. Finally, Filley et $\mathrm{al}^{6}$ hypothesized that toluene-induced cognitive dysfunction may be directly attributed to cerebral white matter involvement. However, the results of other studies indicate the possibility that the cortex is involved in the development of toluene-induced cognitive impairments. ${ }^{21,22}$

The autopsy findings of a chronic toluene abuser showed severe neuronal loss in the second, third, and sixth layers of the cerebral cortex, in addition to widespread demyelination and giant axonopathy in the white matter. ${ }^{21}$ This autopsy revealed that long-term toluene exposure may affect the cerebral cortex as well as white matter. Supporting the findings reported by Escobar and Aruffo, ${ }^{21}$ some animal studies have shown that toluene inhalation causes Purkinje cell loss in the cerebellum and neuronal loss in the hippocampus of rats. ${ }^{23}$ Moreover, Von Euler et $\mathrm{al}^{22}$ showed that chronic toluene exposure causes impairment in spatial memory and reduced cortical area in the parietal cortex of rats. Taken together, the results of these studies indicate that cortical involvement may contribute to the development of toluene-induced cognitive impairments.

In the current study, we assessed the effects of chronic toluene abuse on cortical gray matter volume. We also assessed the association between cognitive functions and cortical gray matter volume distribution in chronic toluene abusers. We did not have an a priori hypothesis about the localization of cortical gray matter volume changes, and we used a voxelbased whole-brain statistical analysis method to assess the cortical gray matter volume differences.

\section{Materials and Methods}

\section{Subjects}

We studied adolescents between 12 and 19 years of age who regularly abused toluene-containing solvents by inhalation for a period of at least 6 months. Toluene abusers were recruited among adolescents who were admitted to a rehabilitation program for solvent abusers. The common solvent abused by all the participants was paint thinner. The patients who abused other substances, such as marijuana, amphetamines, and cocaine, were excluded from the study. The exclusion criteria for the toluene abusers and control subjects also included any contraindications for MR imaging, a history of any disorders known to cause cognitive deficits other than toluene-induced cognitive dysfunctions, neurodegenerative or demyelinating diseases, history of seizures, central nervous system infection, cerebrovascular disease, diabetes mellitus, steroid treatment for any reason, head trauma causing loss of consciousness or requiring hospitalization, a history of a previous psychotic or manic episode, a history of previous treatment with an antipsychotic agent, and a parental history of any psychotic disorder.

Sixteen male chronic toluene abusers meeting the defined criteria were included in the study (mean age, 15.5 years). The information about age of onset for toluene abuse and total duration of toluene abuse was gathered from the abusers and their parents by using a structured interview. Calculation of the absolute daily dosage of inhaled toluene was impossible because of the easy vaporization of thinners and issues related to the methods of abuse that made such calculations impossible, such as variability in the frequency of huffing, the amount of thinner inhaled during each huffing episode, and different physical properties of the rags used. Therefore, we used the amount of thinner bought weekly (as cans per week) to represent the amount of weekly toluene consumption. ${ }^{14}$ Data on the prevalence and amount of weekly alcohol consumption and tobacco smoking among the abusers and control subjects were also collected. Because the subjects did not have regular income, the frequency of alcohol intake was irregular in both groups. Therefore, the amount of weekly alcohol consumption was calculated by considering the number of consumed drinks during their last drinking week (12-g alcohol per drink).

Twenty sex-, age-, and education-level-matched and righthanded (headedness-matched with the abusers) healthy control subjects were recruited from the community (mean age, 15.6 years). The control subjects had no history of substance or drug abuse. All the toluene abusers and control subjects were right-handed (based on the Edinburg Handedness Inventory). Written informed consent was obtained from subjects who were $\geq 18$ years of age during the study. If the subject was $<18$ years of age, written informed consent was obtained from his or her parent. The study was approved by the local Human Subjects Committee.

\section{Cognitive Assessment}

General cognitive functions and intellectual abilities of all subjects were assessed by using the third edition of the Wechsler Intelligence Scale for Children (WISC-III). The WISC-III battery consists of 6 verbal and 5 performance scale subtests. Verbal and performance scores and a full-scale intelligence quotient (FSIQ) of all subjects were calculated. WISC-III tests and MR imaging studies of the toluene abusers were performed at least 3 weeks after their last solvent use to avoid the acute effects of toluene.

\section{Image Acquisition}

Cranial MR imaging studies were performed on a 1.5T superconducting whole-body MR imaging system (Symphony Maestro; Siemens Medical Systems, Erlangen, Germany) with a standard quadrature head coil. High-resolution anatomic images of the whole brain were acquired from the solvent abusers and control subjects with a T1weighted magnetization-prepared rapid acquisition of gradient echo sequence $(\mathrm{TR}=11.08 \mathrm{~ms}, \mathrm{TE}=4 \mathrm{~ms}, \mathrm{TI}=300 \mathrm{~ms}$, relaxation delay time $=500 \mathrm{~ms}, \mathrm{FA}=15^{\circ}, \mathrm{FOV}=256 \times 192 \mathrm{~mm}$, matrix size $=256 \times$ 192 ) yielding 128 sagittal sections with a defined voxel size of $1 \times 1 \times$ $1.3 \mathrm{~mm}$. We also obtained axial fast spin-echo T2-weighted images $(\mathrm{TR}=9200 \mathrm{~ms}, \mathrm{TE}=110 \mathrm{~ms}$, number of acquisitions $=3)$ from all of the subjects to search for any pathologic findings defined in the study exclusion criteria.

\section{Voxel-Based Morphometry Preprocessing}

Data analysis was performed by using the SPM5 software package (Wellcome Department of Cognitive Neurology, London, UK) running under Matlab 2007a (MathWorks, Natick, Mass). We used the VBM5 toolbox (http://dbm.neuro.uni-jena.de) for image preprocessing, which included normalization, segmentation, and modulation steps. ${ }^{24,25}$ The VBM5 toolbox uses a new tissue-segmentation method implemented in SPM5. The details of the unified segmentation method performed in VBM5.1 toolbox have been described elsewhere. ${ }^{25}$ The segmented images were modulated with the Jacobian 


\begin{tabular}{lccr}
\hline & $\begin{array}{c}\text { Abusers } \\
(n=15)\end{array}$ & $\begin{array}{c}\text { Control Subjects } \\
(n=20)\end{array}$ & $P$ Value \\
\hline Age (yr) & $15.53 \pm 1.30$ & $15.60 \pm 1.09$ & $.44(\mathrm{~ns})$ \\
Education (yr) & $6.53 \pm 2.55$ & $7.75 \pm 1.20$ & $.07(\mathrm{~ns})$ \\
Prevalence of alcohol consumption (\%) & $7 / 15(46 \%)$ & $7 / 20(35 \%)$ & $.48(\mathrm{~ns})$ \\
Prevalence of tobacco smoking (\%) & $9 / 15(60 \%)$ & $11 / 20(55 \%)$ & $.76(\mathrm{~ns})$ \\
Amount of weekly alcohol intake (g/week) & $16.00 \pm 22.06$ & $10.80 \pm 16.47$ & $.31(\mathrm{~ns})$ \\
Amount of smoking (cigarettes/day) & $8.53 \pm 4.47$ & - & $-21(\mathrm{~ns})$ \\
Age at onset of abuse (yr) & $12.76 \pm 1.83$ & - & \\
Duration of abuse (months) & $31.86 \pm 18.74$ & - & \\
Weekly inhalant use (cans/week) & $12.60 \pm 0.77$ & $99.75 \pm 4.22$ & \\
WISC-III results & & $100.05 \pm 3.85$ & .001 \\
$\quad$ Performance scale scores & $60.80 \pm 12.88$ & $100.40 \pm 4.00$ \\
Verbal scale scores & $67.13 \pm 12.44$ & .008 \\
FSIO scores & $63.06 \pm 15.97$ & .005 \\
\hline
\end{tabular}

Note:-FSIQ indicates full-scale intelligence quotient; WISC-III, Wechsler Intelligence Scale for Children; ns, not significant; -, no data.

determinants of the deformation parameters obtained by normalization to the Montreal Neurologic Institute standard space to analyze volume differences. Finally, the modulated gray matter images were smoothed with a 10-mm full width at half maximum gaussian kernel and statistically analyzed. The total intracranial volume was included as a covariate during statistical analysis.

\section{Statistical Analysis}

We investigated the regionally specific gray matter volume differences between the toluene abusers and control subjects by using voxel-byvoxel analysis of the covariance test. The total intracranial volumes of the subjects were entered as a covariate. Because the abusers and control groups did not show significant differences in age and sex distribution, tobacco use, and education levels, we did not enter these variables as covariates. Because the difference between the mean amounts of weekly alcohol consumption of the abusers and control subjects was not significant, we did not consider alcohol consumption as a covariate in the voxel-based morphometry analysis. The findings were considered significant at a voxel level of $P<.05$, family-wise error (FWE) corrected, with an extended threshold looking for clusters with at least 10 contiguous voxels. The relationship between the duration of toluene abuse and cortical gray matter volume distribution was evaluated with regression analysis $(P<.05$, FWE corrected). The association was also assessed between the scores obtained from the performance, verbal subtests, and FSIQ on one hand and the cortical gray matter volume changes on the other.

The differences in demographic findings between the toluene abusers and control subjects were investigated by using Mann-Whitney $U$ test, as integrated in the Statistical Package for the Social Sciences, Version 15.0 for Microsoft Windows (SPSS, Chicago, Ill). The differences in the prevalence of alcohol consumption and tobacco smoking were tested by using the $\chi^{2}$ test. The correlations of the scores obtained from the WISC tests with duration of abuse and with weekly solvent consumption were assessed by using linear regression analysis.

\section{Results}

The demographic findings of the toluene abusers and control subjects are given in Table 1. The differences in age or education levels between the toluene abusers and control subjects were not significant $(P>.05)$. The prevalence of alcohol use and the amount of weekly alcohol consumption between the abusers and control subjects were not significant $(P>.05)$.
There was no significant difference in the prevalence of tobacco smoking and the amount of daily tobacco consumption between the toluene abusers and control subjects $(P>.05)$. The scores obtained from the performance and verbal subtests of the WISC-III and the FSIQ scores of the toluene abusers were significantly below the scores obtained from the control subjects $(P<.01$; Table 1$)$. The performance scale scores were slightly lower than the verbal scale scores in the toluene abusers $(P=.46)$. The WISC-III scores of the toluene abusers correlated negatively with the duration of toluene abuse $(P<$ $.05)$. There was no correlation between the WISC-III scores of the abusers and the amount of weekly solvent consumption $(P>.05)$.

The voxel-based image analysis revealed lower cortical gray matter volumes in the abusers than in the control subjects in the following brain regions: bilateral medial frontal gyrus (Brodmann areas [BAs] 9 and 10); right orbitofrontal (BA 11), right superior frontal gyrus (BA 8), right angular gyrus (BA 39 ), right superior parietal lobule (BA 7), right parahippocampal gyrus (BA 36), and left middle temporal gyrus (BA 22) (Fig 1 and Table 2). The duration of toluene abuse correlated negatively with the cortical gray matter volumes of the toluene abusers in the right superior frontal gyrus (BA 6), right inferior temporal gyrus (BA 20), right superior temporal gyrus (BA 22), right occipital lobe (BA 19), left middle frontal gyrus (BA 9), left inferior temporal gyrus (BA 37), and left precentral gyrus (BA 6) (Fig 2 and Table 3). The reduced gray matter volumes in the left middle frontal gyrus (BA 9) and the right superior parietal lobule (BA 7) of the abusers correlated with lower WISC-III performance scale scores (Fig 3 and Table 4). The voxel-based regression analysis showed that in none of the brain regions examined did the gray matter volume correlate significantly with weekly solvent consumption.

\section{Discussion}

In this study, we investigated the adverse affects of chronic toluene exposure on cognitive functions and gray matter morphology. We found that chronic toluene abusers had significantly lower WISC-III IQ scores than healthy control subjects. The performance scale of WISC-III consists of tests measuring visuospatial skills and information-processing speed such as picture completion, block design, and digit-symbol coding. However, the verbal scale subtests of the WISC-III assess lan- 


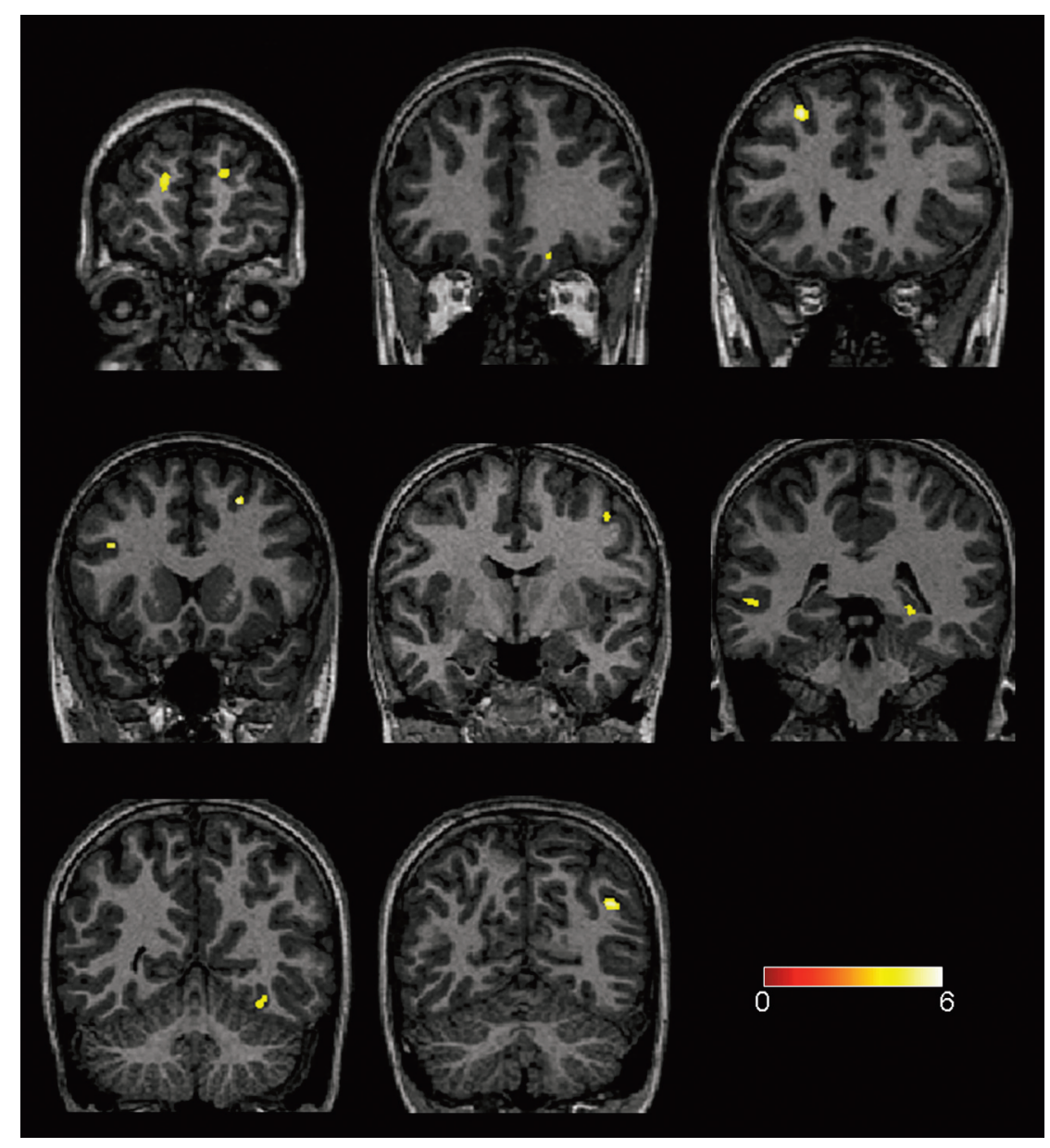

Fig 1. Significant gray matter volume decreases in the toluene abusers compared with the control subjects $(P<.05$, FWE-corrected). $T$ values of cluster with a significant decrease are overlaid on the normalized T1-weighted images of a control subject.

\begin{tabular}{|c|c|c|c|c|c|c|}
\hline \multirow[b]{2}{*}{ Anatomic Regions } & \multirow[b]{2}{*}{ BA } & \multicolumn{3}{|c|}{$\begin{array}{l}\text { Talairach } \\
\text { Coordinates }\end{array}$} & \multirow{2}{*}{$\begin{array}{l}\text { Max. } \\
T \text { value }\end{array}$} & \multirow{2}{*}{$\begin{array}{c}\text { Cluster } \\
\text { Size }\end{array}$} \\
\hline & & $\mathrm{x}$ & $Y$ & Z & & \\
\hline Right medial frontal gyrus & 10 & 15 & 59 & 17 & 4.98 & 34 \\
\hline Right superior frontal gyrus & 8 & 23 & 19 & 47 & 5.26 & 38 \\
\hline Right orbitofrontal gyrus & 11 & 16 & 34 & -19 & 4.75 & 16 \\
\hline Right middle frontal gyrus & 8 & 24 & -19 & 47 & 5.43 & 36 \\
\hline Right precentral gyrus & 6 & 47 & -7 & 47 & 5.18 & 32 \\
\hline Right superior parietal lobule & 7 & 17 & -47 & 59 & 5.67 & 57 \\
\hline Right angular gyrus & 39 & 44 & -62 & 31 & 5.21 & 43 \\
\hline Right parahippocampal gyrus & 36 & 25 & -40 & -4 & 4.99 & 27 \\
\hline Left medial frontal gyrus & 10 & -10 & 58 & 14 & 5.23 & 42 \\
\hline Left middle frontal gyrus & 8 & -24 & 23 & 46 & 4.55 & 68 \\
\hline Left middle frontal gyrus. & 9 & -42 & 19 & 27 & 5.36 & 26 \\
\hline Left middle temporal gyrus & 22 & -53 & -38 & 1 & 5.08 & 37 \\
\hline
\end{tabular}

Note:-BA indicates Brodmann area; Max., maximum.

guage skills, such as comprehension, vocabulary, and similarities between objects or concepts. In the current study, both the verbal and performance scale scores of the toluene abusers were slightly lower than those of the control subjects. Nevertheless, the performance scale scores were significantly lower than the verbal scale scores in the toluene abusers. Thus, the results of the current study show that the visuospatial abilities of toluene abusers were more severely impaired than their language skills. The previous neuropsychological studies in chronic toluene abusers reported a pattern of neurocognitive disturbance consisting of impaired attention, informationprocessing speed, executive function, learning and memory, visuospatial dysfunction, and relatively preserved language skills. ${ }^{2,6,9,11-13}$

Yamanouchi et $\mathrm{al}^{13}$ assessed the cognitive functions of the toluene abusers by using the Wechsler Adult Intelligence Scale (WAIS). With results similar to ours, they found significantly reduced WAIS performance scale scores among abusers, which were associated with the severity of pontine atrophy. In contrast to the results of the current study, they found a relative sparing of language skills. In our study, the negative correlation of the performance scale and FSIQ scores with the duration of abuse indicates that the cognitive deficits of the toluene abusers are related to the long-term toluene exposure.

In the literature, a handful of studies have investigated the effects of long-term toluene exposure on the cerebral cortex. Kucuk et $\mathrm{al}^{26}$ studied cerebral perfusion abnormalities in toluene abusers by using technetium Tc99m hexamethylpropyleneamine oxime single-photon emission CT (SPECT). They found hypo- and hyperperfused regions in the frontal, temporal, and parietal cortices. In another SPECT study, Okada et $\mathrm{al}^{27}$ used iodine 123I inosine monophosphate to measure the cerebral perfusion in the chronic toluene abusers and found significantly decreased cerebral blood flow in the prefrontal 


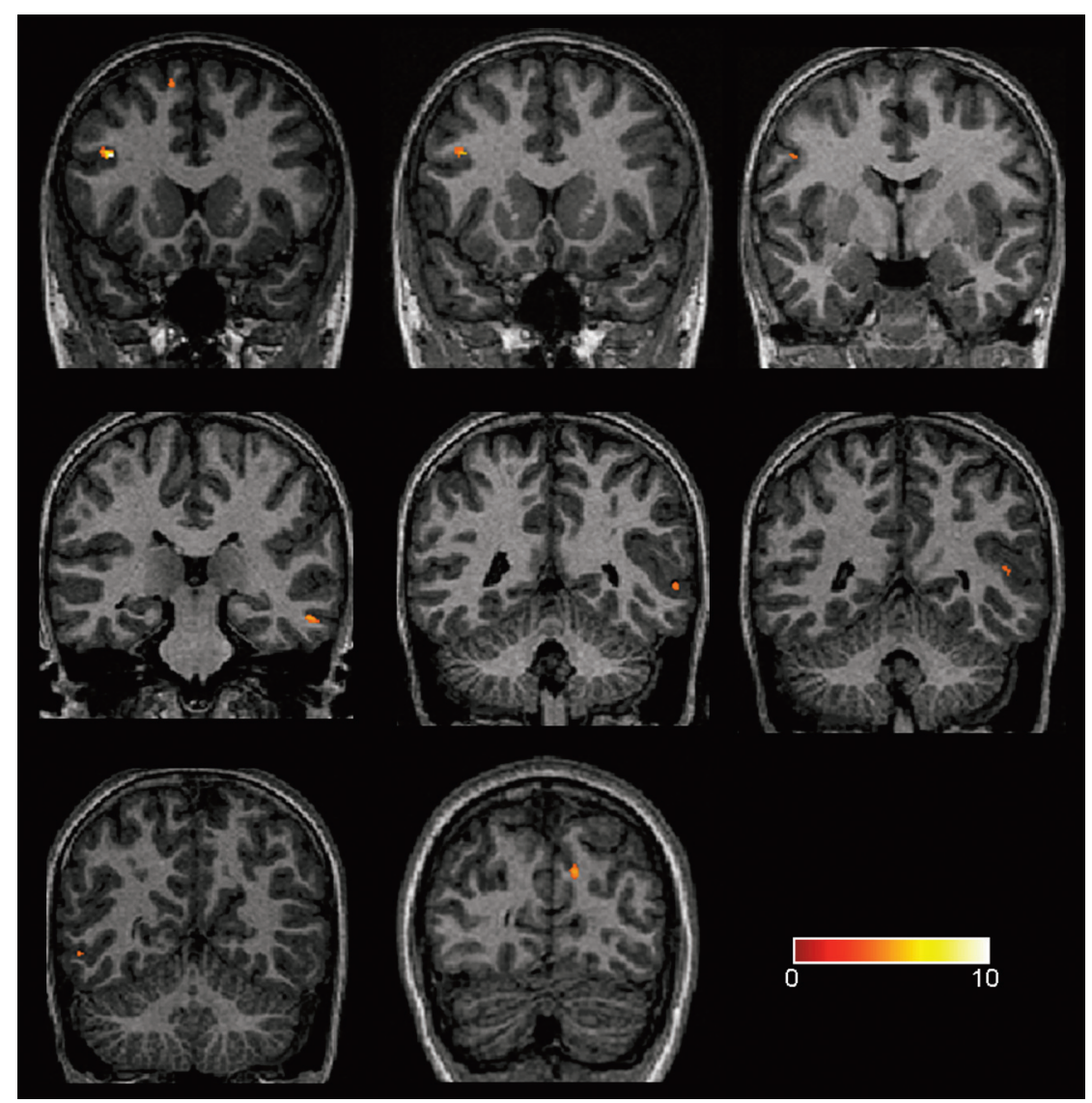

Fig 2. Significant negative correlations between the gray matter volume and duration of toluene abuse $(P<.05$, FWE-corrected). $T$ values of cluster with a significant correlation are overlaid on the normalized T1-weighted images of a control subject.

Table 3: Cortical regions that showed a negative correlation between the gray matter volume and duration of abuse among the toluene abusers

\begin{tabular}{lrrrrrrr}
\hline & \multicolumn{4}{c}{ Talairach } & & \\
\cline { 3 - 5 } & & \multicolumn{1}{c}{ Coordinates } & & Max. & Cluster \\
\cline { 3 - 5 } Anatomic Regions & BA & \multicolumn{1}{c}{ X } & Y & Z & & T Value & Size \\
\hline Right superior frontal gyrus & 6 & 10 & 33 & 53 & 5.78 & 27 \\
Left middle frontal gyrus & 9 & -40 & 18 & 28 & 7.63 & 56 \\
Left precentral gyrus & 6 & -55 & -4 & 35 & 5.45 & 18 \\
Right inferior temporal gyrus & 20 & 57 & -30 & -16 & 5.82 & 27 \\
Right superior temporal gyrus & 22 & 50 & -50 & 9 & 5.38 & 25 \\
Left inferior temporal gyrus & 37 & -55 & -56 & -5 & 5.29 & 22 \\
Right occipital lobe, cuneus & 19 & 10 & -81 & 25 & 5.98 & 31 \\
\hline
\end{tabular}

cortex. Furthermore, the hypoperfusion in the prefrontal cortex was related to behavioral disturbances observed in the abusers. In an animal study, Von Euler et $\mathrm{al}^{22}$ investigated the effects of long-term toluene exposure on the behavior and brain sizes of rats. They found that toluene exposure led to the impairment of visuospatial skills and selective decrease in the parietal cortex size of the rats.

In our study, the voxel-based comparison revealed significantly lower gray matter volumes at multiple locations within the cerebral cortex of the toluene abusers compared with the control subjects. The correlation of lower gray matter volumes in the frontal, temporal, and occipital lobes with the duration of toluene abuse demonstrates the association of the gray matter loss with long-term toluene exposure. Previous animal studies showed that chronic toluene changes in the $\mathrm{N}$-methyl $\mathrm{D}$-aspartate receptor subunits in the medial prefrontal cortex of rats suggest an increase in neuronal excitability. ${ }^{2}$ These findings highlight the potential for excitotoxic neuronal damage with chronic toluene exposure. ${ }^{2}$

Cerebral cortical gray matter is composed of neurons and glia in a laminar arrangement. Neurodegenerative disorders leading to neuronal loss cause cortical gray matter volume reduction, which can be detected by morphometric MR imaging analysis. ${ }^{28,29}$ In the current study, the smaller gray matter volumes in the toluene abusers may be associated with neuronal loss in the related regions of the brain. Consistent with this hypothesis, animal studies have shown that long-term toluene inhalation causes neuronal loss in the hippocampal region of rats. ${ }^{23}$ Furthermore, the autopsy findings of a chronic toluene abuser revealed decreased neuronal attenuation in the cerebral cortex. ${ }^{21}$ In that study, the investigators found severely damaged second, third, and sixth neuronal layers of the parietal cortex. Reactive gliosis and vacuolation of myelin sheaths accompanied the neuronal loss. Aydin et $\mathrm{al}^{15}$ conducted a proton MR spectroscopy study to investigate neurochemical changes in the thalamus and white matter of toluene abusers. $\mathrm{N}$-acetylaspartate (NAA) levels were reduced in the cerebral white matter, which indicated an impairment of the neuroaxonal integrity. However, as acknowledged by the authors, neurochemical changes in the cerebral cortex were not assessed, and the source of the reduced NAA level in white matter could not be specified. Neuronal loss, together with axonal and my- 


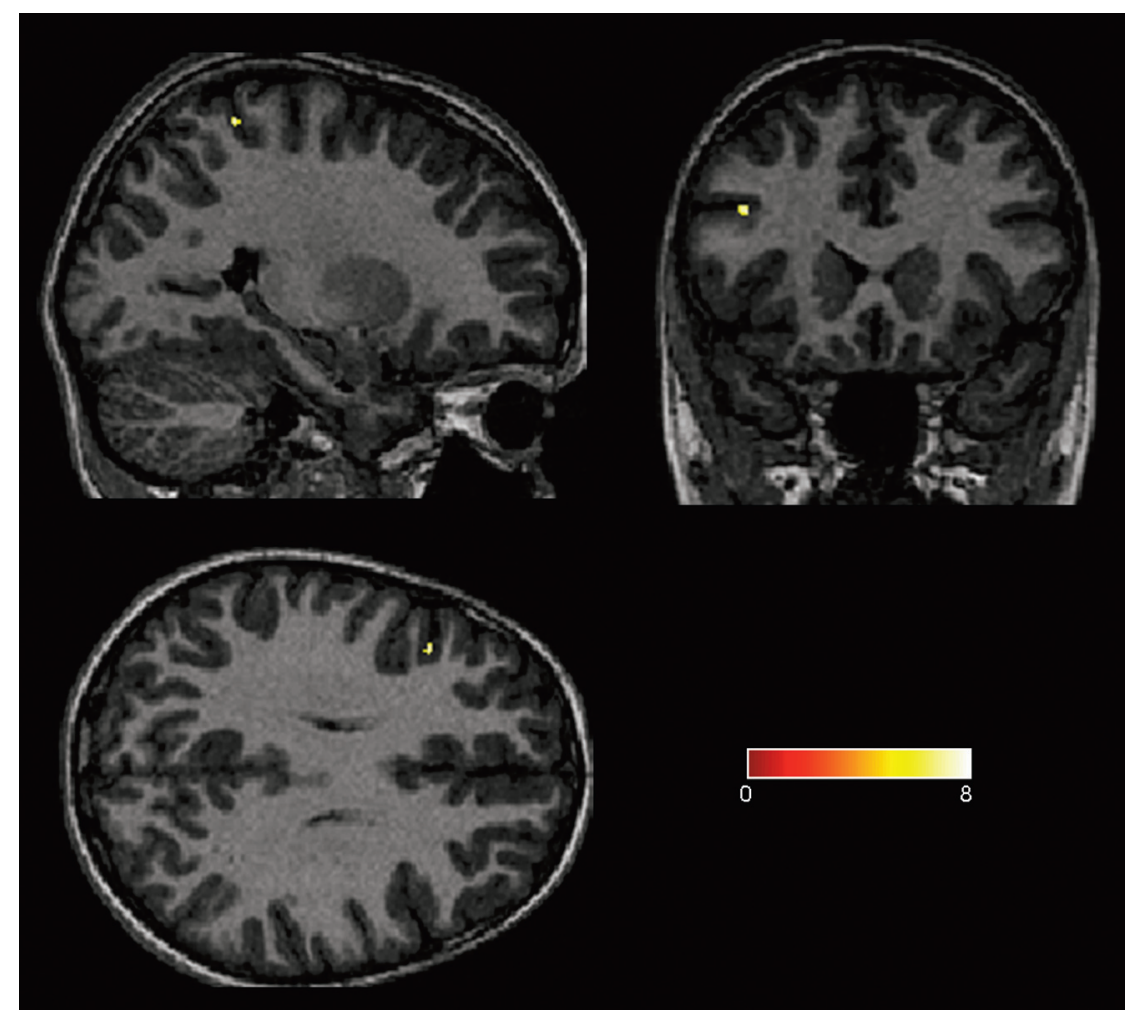

Fig 3. Significant positive correlations between the gray matter volume and WISC performance scale scores of the toluene abusers $(P<.05$, FWE-corrected). $T$ values of cluster with a significant correlation are overlaid on the normalized T1-weighted images of a control subject.

Table 4: Cortical regions in which the cortical gray matter volumes were positively correlated with the Wechsler performance scale scores of the toluene abusers

\begin{tabular}{|c|c|c|c|c|c|c|}
\hline \multirow[b]{2}{*}{ Anatomic Regions } & \multirow[b]{2}{*}{$\mathrm{BA}$} & \multicolumn{3}{|c|}{$\begin{array}{c}\text { Talairach } \\
\text { Coordinates }\end{array}$} & \multirow{2}{*}{$\begin{array}{c}\text { Max. } \\
T \text { Value }\end{array}$} & \multirow{2}{*}{$\begin{array}{c}\text { Cluster } \\
\text { Size }\end{array}$} \\
\hline & & $x$ & $Y$ & $\bar{Z}$ & & \\
\hline Left middle frontal gyrus & 9 & -41 & 20 & 26 & 7.45 & 29 \\
\hline Right superior parietal lobule & 7 & 26 & -47 & 61 & 7.08 & 21 \\
\hline
\end{tabular}

elin damage, may have been related to the reduction of the NAA level in white matter.

In the current study, we also report a significant correlation of the WISC-III performance scale scores with the lower gray matter volumes in the dorsolateral prefrontal cortex (BA 9) and superior parietal lobule (BA 7) of toluene abusers. According to the parietofrontal integration theory of intelligence, BA 7 and BA 9 are the key regions that form the core of general intelligence. ${ }^{30,31}$ The superior parietal lobule (BA 7) is the somatosensory association region that is involved in visuospatial processing. Previous functional studies have shown that processing of $3 \mathrm{D}$ object imagination, mental rotation of objects, and perspective-taking are related to the function of the superior parietal lobule. ${ }^{32-34}$ Previous studies have also shown an association between visuospatial intelligence and increased gray matter volume in the superior parietal lobule. ${ }^{35}$ The performance scale of WISC-III is based mainly on visuospatial skills, such as object assembly and block design. In the present study, the smaller gray matter volumes in the superior parietal lobule of the toluene abusers may be associated with the impairment of the visuospatial skills and lower WISC-III performance scale scores.
The dorsolateral prefrontal cortex (BA 9) is involved in the processing of working memory. Previous functional studies have shown that tasks that stimulate working memory cause strong activation of the dorsolateral prefrontal cortex. ${ }^{36,37}$ Together with BA 11 and 10 regions, the dorsolateral prefrontal cortex is also involved in planning, reasoning, decision-making, and executive functioning. Working memory is one of the core structures of general intelligence. ${ }^{30,38}$ Any factor that causes impairment in working memory leads to a decrease in all components of intelligence. Previous studies have shown that the gray matter volume in BA 9 correlates with both verbal and spatial intelligence. ${ }^{39}$ Thus, the gray matter loss in the dorsolateral prefrontal cortex may be related to the lower WISC-III scores in the toluene abusers.

A few limitations of the current study should be mentioned. First, the current study had a cross-sectional design. Because most of the abusers did not consent to a second MR imaging scan, we could not perform a longitudinal study. A longitudinal study for a long period of time would give valuable information about the evolution of gray matter volume and cognitive functions. Second, we recruited healthy control subjects who were matched with the abusers in age, sex, and education level. However, the solvent abusers may have had other psychosocial premorbid factors that may have affected the results. Finally, this study did not investigate the effects of toluene abuse on white matter. Future studies that use advanced and quantitative white matter imaging methods, such as diffusion tensor imaging and magnetization transfer imaging, may help to clarify the relationship between cognitive dysfunctions and white matter changes in toluene abusers.

In conclusion, the results of the current study show that 
chronic toluene abusers have smaller gray matter volumes than nonabusers in various regions of the brain. Moreover, the cognitive deficits are associated with the lower gray matter volumes in the frontal and parietal cortices of chronic toluene abusers.

\section{References}

1. Clinger OW, Johnson NA. Purposeful inhalation of gasoline vapors. Psychiatr Q 1951;25:557-67

2. Lubman DI, Yücel M, Lawrence AJ. Inhalant abuse among adolescents: neurobiological considerations. Br J Pharmacol 2008;154:316-26

3. Medina-Mora ME, Real T. Epidemiology of inhalant use. Curr Opin Psychiatry 2008;21:247-51

4. Yücel M, Takagi M, Walterfang M, et al. Toluene misuse and long-term harms: a systematic review of the neuropsychological and neuroimaging literature. Neurosci Biobehav Rev 2008;32:910-26. Epub 2008 Mar 2

5. Lubman DI, Hides L, Yücel M. Inhalant misuse in youth: the need for a coordinated response. Med J Aust 2006;185:327-30

6. Filley CM, Halliday W, Kleinschmidt-DeMasters BK. The effects of toluene on the central nervous system. J Neuropathol Exp Neurol 2004;63:1-12

7. Hormes JT, Filley CM, Rosenberg NL. Neurological sequelae of chronic solvent vapor abuse. Neurology 1986;36:698-702

8. Knox JW, Nelson JR. Permanent encephalopathy from toluene inhalation. N Engl J Med 1966;275:1494-96

9. Rosenberg NL, Kleinschmidt-DeMasters BK, Davis KA, et al. Toluene abuse causes diffuse central nervous system white matter changes. Ann Neurol 1988;23:611-14

10. Greenberg MM. The central nervous system and exposure to toluene: a risk characterization. Environ Res 1997;72:1-7

11. Filley $\mathrm{C}$, Heaton RK, Rosenberg NL. White matter dementia in chronic toluene abuse. Neurology 1990;40:532-34

12. Rosenberg NL, Grigsby J, Dreisbach J, et al. Neuropsychologic impairment and MRI abnormalities associated with chronic solvent abuse. J Toxicol Clin Toxicol 2002;40:21-34

13. Yamanouchi N, Okada S, Kodama K, et al. Effects of MRI abnormalities on WAIS-R performance in solvent abusers. Acta Neurol Scand 1997;96:34-39

14. Aydin K, Sencer S, Demir T, et al. Cranial MR findings in chronic toluene abuse by inhalation. AJNR Am J Neuroradiol 2002;23:1173-79

15. Aydin K, Sencer S, Ogel K, et al. Single-voxel proton MR spectroscopy in toluene abuse. Magn Reson Imaging 2003;21:777-85

16. Caldemeyer K, Pascuzzi R, Moran C, et al. Toluene abuse causing reduced MR signal intensity in the brain. AJR Am J Roentgenol 1993;161:1259-61

17. Xiong L, Matthes LD, Li J, et al. MR imaging of "spray heads": toluene abuse via aerosol paint inhalation. AJNR Am J Neuroradiol 1993;14:1195-99

18. Yamanouchi N, Okada S, Kodama K, et al. White matter changes caused by chronic solvent abuse. AJNR Am J Neuroradiol 1995;16:1643-49
19. Kamran S, Bakshi R. MRI in chronic toluene abuse: low signal in the cerebral cortex on T2-weighted images. Neuroradiology 1998;40:519-21

20. Unger E, Alexander A, Fritz T, et al. Toluene abuse: physical basis for hypointensity on T2-weighted images. Radiology 1994;193:473-76

21. Escobar A, Aruffo C. Chronic thinner intoxication: clinico-pathologic report of a human case. J Neurol Neurosurg Psychiatry 1980;43:986-94

22. Von Euler M, Pham TM, Hillfors M, et al. Inhalation of low concentrations of toluene induces persistent effects on a learning retention task, beam-walk performance, and cerebrocortical size in the rat. Exp Neurol 2000;163:1-8

23. Korbo L, Ladefoged O, Lam HR, et al. Neuronal loss in hippocampus in rats exposed to toluene. Neurotoxicology 1996;17:359-66

24. Asburner J, Friston KJ. Voxel-based morphometry: the methods. Neuroimage 2000;11:805-21

25. Meisenzahl EM, Koutsouleris N, Gaser C, et al. Structural brain alterations in subjects at high-risk of psychosis: a voxel-based morphometry study. Schizophr Res 2008;102:150-62

26. Kucuk N, Kilic E, Ibis E, et al. Brain SPECT findings in long-term inhalant abuse. Nucl Med Commun 2000;21:769-73

27. Okada S, Yamanouchi N, Kodama K, et al. Regional cerebral blood flow abnormalities in chronic solvent abusers. Psychiatry Clin Neurosci 1999;53:351-56

28. Hirata Y, Matsuda H, Nemoto K, et al. Voxel-based morphometry to discriminate early Alzheimer's disease from controls. Neuosci Lett 2005;382:269-74. Epub 2005 Apr 14

29. Karas GB, Burton EJ, Rombouts SA, et al. A comprehensive study of gray matter loss in patients with Alzheimer's disease using optimized morphometry. Neuroimage 2003;18:895-907

30. Colom R, Abad FJ, Quiroga MA, et al. Working memory and intelligence are highly related construct, but why? Intelligence 2008;36:584-606

31. Jung RE, Haier RJ. The parieto-frontal integration theory (P-FIT) of intelligence: converging neuroimaging evidence. Behav Brain Sci 2007;30:13587, discussion 154-87. Epub 2007 Jul 26

32. Gauthier I, Hayward WG, Tarr MJ, et al. BOLD activity during mental rotation and viewpoint-dependent object recognition. Neuron 2002;34:161-71

33. Jackson PL, Meltzoff AN, Decety J. Neural circuits involved in imitation and perspective-taking. Neuroimage 2006;31:429-39. Epub 2006 Jan 10

34. Zago L, Tzourio-Mazoyer N. Distinguishing visuospatial working memory and complex mental calculation areas within the parietal lobes. Neurosci Lett 2002;331:45-49

35. Bühner M, Kröner S, Ziegler M. Working memory, visual-spatial-intelligence and their relationship to problem-solving. Intelligence 2008;36:672-80

36. Olese $\mathrm{PJ}$, Westerberg $\mathrm{H}$, Klingberg $\mathrm{T}$. Increased prefrontal and parietal activity after training of working memory. Nat Neurosci 2004;7:75-59

37. Smith EE, Jonides J. Storage and executive processes in the frontal lobes. Science 1999;283:1657-61

38. Conway ARA, Kane MJ, Engle RW. Working memory capacity and its relation to general intelligence. Trends Cogn Sci 2003;7:547-52

39. Colom R, Haier RJ, Head K, et al. Gray matter correlates of fluid, crystallized, and spatial intelligence: testing the P-FIT model. Intelligence 2008;37:124-35 